\title{
Recent advances in voltage-gated sodium channels, their pharmacology, and related diseases
}

\author{
Jean-François Desaphy ${ }^{1 *}$ and Mohamed Chahine ${ }^{2}$ \\ 1 Section of Pharmacology, Department of Pharmacy and Drug Sciences, University of Bari - Aldo Moro, Bari, Italy \\ 2 Department of Medicine, Centre de Recherche de I'IUSMO, Laval University, Québec, OC, Canada \\ *Correspondence: jfdesaphy@farmbiol.uniba.it
}

Edited by:

Philippe Lory, CNRS and University of Montpellier, France

Because of their fundamental role in generating electrical impulses in many excitable tissues, sodium channels were among the first voltage-gated ion channels to be extensively investigated. Neurons bathed in a physiological solution containing $150 \mathrm{mM}$ sodium ions respond to a threshold electrical stimulus by generating an action potential, whereas such a response is abolished in a $\mathrm{Na}^{+}$-free medium. Since the classic 1952 studies of squid axon sodium conductance, the Hodgkin and Huxley model of sodium channel gating has served as a framework for understanding the time and voltage-dependent properties of these channels (Hodgkin and Huxley, 1952). The advent of sophisticated biochemical and molecular approaches eventually lead to sodium channel purification (Hartshorne and Catterall, 1981) and cloning (Noda et al., 1984). To date nine genes encoding voltage-gated sodium channels are found in the human genome. Dysfunction of these channels causes diseases known as sodium channelopathies. In the 1990's, the term "channelopathy" was first coined to describe skeletal muscle hereditary diseases, including periodic paralysis and myotonia, due to mutations in the SCN4A gene encoding the muscle isoform of voltage-gated sodium channels (Wang et al., 1993). Many of these aspects are reviewed in this special issue dedicated to voltage-gated sodium channels (Simkin and Bendahhou, 2011; Savio-Galimberti et al., 2012).

Despite this impressive track record, there are still a number of critical questions that need to be addressed regarding voltagegated sodium channels. Up to day, many studies have focused on the main sodium channel $\alpha$-subunit because it contains all the requisites for a functioning channel, but it has become clear that the $\alpha$-subunit interacts with auxiliary $\beta$-subunits and other protein partners, that regulate the trafficking, the expression levels

\section{REFERENCES}

Brackenbury, W. J., and Isom, L. L. (2011). $\mathrm{Na}^{+}$channel $\beta$ subunits: overachievers of the ion channel family. Front. Pharmacol. 2:53. doi: 10.3389/fphar.2011.00053

Chahine, M., and O'Leary, M. E. (2011). Regulatory role of voltagegated $\mathrm{Na}+$ channel beta subunits in sensory neurons. Front. Pharmacol. 2:70. doi: 10.3389/fphar.2011.00070

Conte Camerino, D., Tricarico, D., and Desaphy, J. F. (2007). Ion channel pharmacology. Neurotherapeutics 4, 184-198.
Desaphy, J.-F., Dipalma, A., Costanza, T., Carbonara, R., Dinardo, M. M., Catalano, A., et al. (2012). Molecular insights into the local anesthetic receptor within voltagegated sodium channels using hydroxylated analogs of mexiletine. Front. Pharmacol. 3:17. doi: 10.3389/fphar.2012.00017

Fozzard, H. A., Sheets, M. F., and Hanck, D. A. (2011). The sodium channel as a target for local anesthetic drugs. Front. Pharmacol. 2:68. doi: 10.3389/fphar.2011 00068

and the function of these channels (Brackenbury and Isom, 2011; Chahine and O'Leary, 2011; Savio-Galimberti et al., 2012).

Today voltage-gated sodium channels are the primary targets of drugs used as local anaesthetics, antiarrhythmics, anticonvulsants, and neuroprotectants (Conte Camerino et al., 2007). Several ongoing studies are aimed at understanding the intimate drug-channel molecular interactions to design more efficacious and safer drugs (Fozzard et al., 2011; Desaphy et al., 2012; Morris et al., 2012). Gating properties of these channels are also affected during trauma injury (Morris et al., 2012). As far as our knowledge increases regarding sodium channel biophysics and involvement in diseases, sodium channels represent a more, and more attractive druggable targets for other conditions such as neuropathic pain and general anesthesia (Theile and Cummins, 2011; Herold and Hemmings, 2012). Voltage-gated sodium channels are also the targets of numerous natural ligands, especially neurotoxins, which provide important tools for the definition of the channel structure-activity relationship, and ideally may serve as lead compounds in the development of novel drugs (Stevens et al., 2011). Thus, voltage-gated sodium channels will likely continue to exert much interest for basic scientists and the pharmaceutical industry. This topic is dedicated to voltage-gated sodium channels their pharmacology and related diseases.

\section{ACKNOWLEDGMENTS}

Mohamed Chahine's studies are supported by grants from the Heart and Stroke Foundation of Quebec (HSFQ) and the Canadian Institutes of Health Research (CIHR, MT-13181). Jean-François Desaphy's studies are supported by grants from Telethon-Italy (\#GGP10101) and the Association Française contre les Myopathies (\#15020).

Hartshorne, R. P., and Catterall, W. A. (1981). Purification of the saxitoxin receptor of the sodium channel from rat brain. Proc. Natl. Acad. Sci. U.S.A. 78, 4620-4624.

Herold, K. F., and Hemmings $\mathrm{Jr}$, H. C. (2012). Sodium channels as targets for volatile anesthetics. Front. Pharmacol. 3:50. doi: 10.3389/fphar.2012.00050

Hodgkin, A. L., and Huxley, A. F. (1952). A quantitative description of membrane current and its application to conduction and excitation in nerve. J. Physiol. 117, 500-544.
Morris, C. E., Boucher, P.-A., and Joos, B. (2012). Left-shifted Nav channels in injured bilayer: primary targets for neuroprotective Nav antagonists? Front. Pharmacol. 3:19. doi: 10.3389/fphar.2012.00019

Noda, M., Shimizu, S., Tanabe, T., Takai, T., Kayano, T., Ikeda, T., et al. (1984). Primary structure of Electrophorus electricus sodium channel deduced from cDNA sequence. Nature 312, 121-127.

Savio-Galimberti, E., Gollob, M. H., and Darbar, D (2012). Voltage-gated sodium 
channels: biophysics, pharmacology, and related channelopathies. Front. Pharmacol. 3:124. doi: 10.3389/fphar.2012.00124

Simkin, D., and Bendahhou, S. (2011). Skeletal muscle Na channel disorders. Front. Pharmacol. 2:63. doi: 10.3389/fphar.2011.00063

Stevens, M., Peigneur, S., and Tytgat, J. (2011). Neurotoxins and their binding areas on voltage-gated sodium channels. Front. Pharmacol. 2:71. doi: 10.3389/fphar.2011.00071
Theile, J. W., and Cummins, T. R. (2011). Recent developments regarding voltage-gated sodium channel blockers for the treatment of inherited and acquired neuropathic pain syndromes. Front. Pharmacol. 2:54. doi: 10.3389/fphar.2011.00054

Wang, J., Zhou, J., Todorovic, S. M., Feero, G., Barany, F., Conwit, R., et al. (1993). Molecular genetic and genetic correlations in sodium channelopathies: Lack of founder effect and evidence for a second gene. Am. J. Hum. Genet. 52, 1074-1084.

Received: 27 March 2013; accepted: 04 April 2013; published online: 18 April 2013.

Citation: Desaphy J-F and Chahine $M$ (2013) Recent advances in voltage-gated sodium channels, their pharmacology, and related diseases. Front. Pharmacol. 4:52. doi: 10.3389/fphar.2013.00052
This article was submitted to Frontiers in Pharmacology of Ion Channels and Channelopathies, a specialty of Frontiers in Pharmacology.

Copyright (c) 2013 Desaphy and Chahine. This is an open-access article distributed under the terms of the Creative Commons Attribution License, which permits use, distribution and reproduction in other forums, provided the original authors and source are credited and subject to any copyright notices concerning any third-party graphics etc. 